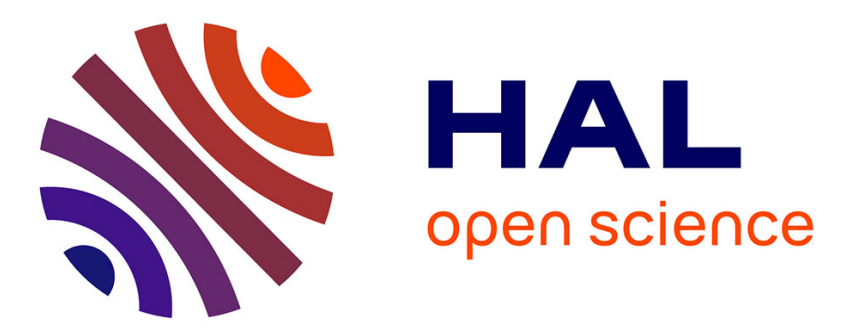

\title{
Flood Modelling and Visualizations of Floods Through 3D Open Data
}

\author{
Lukáš Herman, Jan Russnák, Tomáš Řezník
}

\section{To cite this version:}

Lukáš Herman, Jan Russnák, Tomáš Řezník. Flood Modelling and Visualizations of Floods Through 3D Open Data. 12th International Symposium on Environmental Software Systems (ISESS), May 2017, Zadar, Croatia. pp.139-149, 10.1007/978-3-319-89935-0_12 . hal-01852618

\section{HAL Id: hal-01852618 https://hal.inria.fr/hal-01852618}

Submitted on 2 Aug 2018

HAL is a multi-disciplinary open access archive for the deposit and dissemination of scientific research documents, whether they are published or not. The documents may come from teaching and research institutions in France or abroad, or from public or private research centers.
L'archive ouverte pluridisciplinaire HAL, est destinée au dépôt et à la diffusion de documents scientifiques de niveau recherche, publiés ou non, émanant des établissements d'enseignement et de recherche français ou étrangers, des laboratoires publics ou privés. 


\title{
Flood Modelling and Visualizations of Floods through 3D Open Data
}

\author{
Lukáš Herman, Jan Russnák and Tomáš Řezník \\ Masaryk University, Faculty of Science, Department of Geography, \\ Kotlářská 2, 61137 Brno, Czech Republic \\ herman.lu@mail.muni.cz, russnak@mail.muni.cz, \\ tomas.reznik@sci.muni.cz
}

\begin{abstract}
This paper is devoted to 3D modelling at the city level from data sources considered as open. The open data presented in this paper enable free usage, modifications, and sharing by anyone for any purpose. The main motivation was to verify feasibility of a 3D visualization of floods purely based on open technologies and data. The presented state-of-the-art analysis comprises the evaluation of available 3D open data sources, including formats, Web-based technologies, and software used for visualizations of 3D models. A pilot Web application visualizing floods was developed to verify the applicability of discovered data sources. 3D visualizations of terrain models, 3D buildings, flood areas, flood walls and other related information are available in a pilot application for a selected part of the city of Prague. The management of different types of input data, the design of interactive functionality including navigation aids, and actual limitations and opportunities for future development are discussed in detail at the end.
\end{abstract}

Keywords: 3D modelling, 3D visualizations, floods, open data

\section{Introduction}

Nowadays, 3D geospatial data and technologies for 3D cartographic visualization are being used with increasing frequency in a variety of human activities. Crisis management is no different. Applications of 3D geospatial data and technologies can increase, for example, the awareness and understanding of flood-related issues [17, 26, 35]. 3D visualization may be used by experts and laymen alike in the use case described below. 3D visualization also has the ability to assist in dealing with the problem of flooding on different scales - from the global and regional levels to the local level involving individual towns and cities [14]. Feasibility of a 3D visualization of floods purely based on open technologies and data was is the primary aim of this paper. Solely open data and technologies were used for this purpose; based on an analysis of available sources of open data for the case study area (a part of city of Prague, The Czech Republic).

adfa, p. 1, 2011.

(C) Springer-Verlag Berlin Heidelberg 2011 


\section{Open data and technologies}

"Open Data and content can be freely used, modified, and shared by anyone for any purpose" [34]. This definition was initially derived from the Open Source Definition. Open data are available without access restrictions, licenses, copyright, patents, or charges for access or re-use. The main reasons, why data should be open, are:

- transparency,

- the release of social and commercial value,

- the release of participation,

- the release of engagement.

Because of the variability in open data, when, for example, one organization deploys PDF files while another deploys raw data, Tim Berners-Lee, the inventor of the Web and Open Data supporter, suggested a 5-star deployment scheme for Open Data. The scheme - from scanned tables in PDF, through XLS and CSV, to data that could be linked to other data (e.g. [24]) - is shown in Fig. 1.

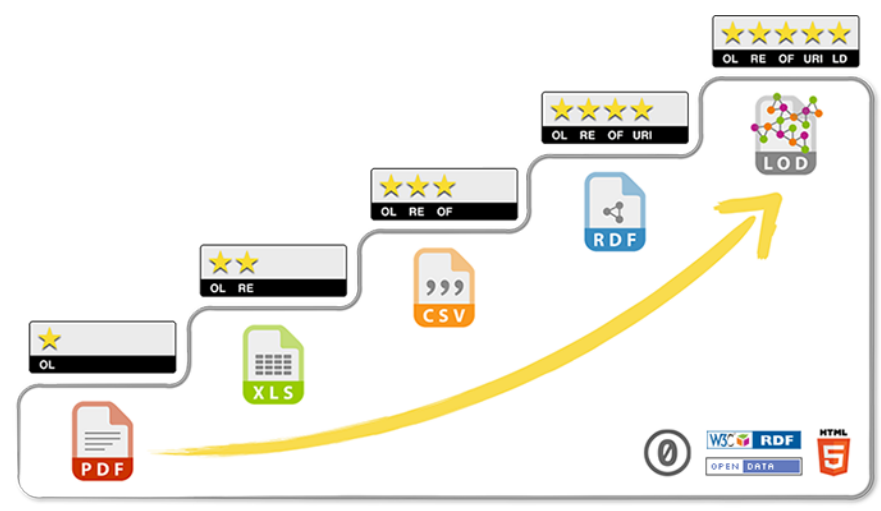

Fig. 1. 5-star schema of Open Data openness (source: [2])

\subsection{Open geospatial data}

There are various projects creating open geospatial data. Precise and detailed geospatial data are not usually open or distributed for free. National mapping agencies or commercial companies usually offer their geospatial data for a fee. Therefore because of such fees, open or free geospatial data are used whenever they are suitable enough. Free data could be licensed (e.g. for limited usage in educational context) unlike Open Data. Open geospatial data have potential uses and applications in various fields such as urban planning, urban studies or 3D city modelling [7, 18], transport analysis and navigation [11], precision farming [24, 25], environmental protection [16], sociology and socio-economic analysis [21], crime analysis [28], and also crisis management, which is the topic of this article. In the following paragraphs we present examples of 
various sources of open geospatial data, with an emphasis on data suitable for 3D modelling

Open geospatial data, or open data in general, are often collected, managed, and then made available by an institution, organization or government. These providers should be responsible for the content. According to the provider, these open data can be termed open government data. The same should also hold for open geospatial data. The most commonly used freely available elevation data sets are derived from the SRTM (Shuttle Radar Topography Mission) and the ASTER GDEM (Advanced Spaceborne Thermal Emission and Reflection Radiometer Global Digital Elevation Model). SRTM DEM (Digital Elevation Model) is the result of a project spearheaded by NASA and NGA (National Geospatial-Intelligence Agency). The pixel size of the raw image represents $30 \mathrm{~m}$ over the USA and Australia. For the rest of the world, the ground resolution is $90 \mathrm{~m}$. The elevation models obtained from SRTM data are freely available from the Internet. Up to 2009, SRTM DEM was the most complete highresolution digital topographic database of the Earth. In 2009, the ASTER GDEM was released. Compared to SRTM DEM, ASTER GDEM covers a larger area of the Earth and the resolution is 30m worldwide. By the end of 2015, all of the highest-resolution data generated from SRTM were also released. [3, 29, 32, 36] EU-DEM is another similar dataset for the pan European region, which is provided by the European Environmental Agency. For the European level, EU-DEM provides downloadable colorshaded relief data with values relating to actual elevations. The EU-DEM is a hybrid product based on SRTM and ASTER GDEM data fused by a weighted averaging approach. The resolution of EU-DEM is 25m. [5]

Meanwhile, the currently most popular open geospatial data source, OpenStreetMap (OSM), is in the form of a Volunteered Geographic Information (VGI) project created by thousands of contributors, which are not responsible for the content or which cannot be held accountable for the content. OSM data can be both transformed from official sources and manually created by voluntary users. For this reason, OSM data should be used with caution, especially if the issue needs detailed (and precise) input data such as the 3D modelling of cities. Some 3D visualizations or 3D models have been created on the basis of OSM data. A basic extension for 3D modeling is Simple 3D Buildings based on the 3D attributes of buildings. On the basis of the heights of building outlines and building parts, 3D buildings are modeled or, for example, roof types are described. Another 3D application based on OSM data is the open source project Open Earth View. Its aim is full 3D web browsing of a world map. The base ground is built by OSM 2D tiles, which are extended by 3D tiles created essentially from SRTM and other accessible elevation data, or from OSM 2D data attributes like building elevation, number of floors, or roof elevation. For conversion from OSM data into a 3D model, OSM2World can also be used. The OSM-3D project combines OSM data and the SRTM DEM on a virtual globe. OSM-3D is a part of the development of a 3D Geodata Infrastructure for the entire World based on open web service standards of the Open Geospatial Consortium (OGC). The project aims to provide a Web-based interactive 3D view of OSM data. OSM Buildings and F4map are two quite similar projects concerning also the 3D visualization of OSM data. [1, 19, 23, 30] 


\section{$2.23 D$ data formats}

Both technologies and standards primarily designed for computer graphics and GIS formats are used to save 3D geospatial data. Probably the oldest most widespread format for interactive 3D computer graphics is VRML (Virtual Reality Modelling Language). VRML is a text file format in which 3D geometry can be specified along with surface colour, texture, transparency, and other properties. X3D (Extensible 3D) is an open standard file format based on XML for the description of spatial scenes. Essentially, it is recognized as the successor to VRML. COLLADA is designed to store 3D graphics; it has similar capabilities to X3D and also the XML structure [4]. There are many other 3D graphics formats besides the above mentioned technologies, and extensions of more conventional (2D) formats, such as 3D PDF, can also be used.

3D spatial objects are also stored through GIS technologies. For example, Multipatch is geometry used in ESRI geodatabases and in Shapefiles to represent 3D features. GML (Geography Markup Language) is an XML grammar defined by the OGC to express geographical features. GML was originally only 2D; however, since version 3.0, it has also been possible to manage 3D data. CityGML is an application schema for GML version 3.1.1 for the storage and exchange of virtual 3D city models. KML (Keyhole Markup Language) is primarily intended for the publication and distribution of geographic data. KML 2.2 was adopted in 2008 as an OGC standard [13].

3D formats can also be classified according to a 5-star scale of data openness. A 3D PDF or Shapefile (Multipatch geometry) can be classified under the 2-star class, other formats like COLLADA, KML, VRML, X3D, GML and CityGML under the 3star class. An important issue for open data formats is their standardization. The most important standardization authority in geoinformatics is OGC. From the above mentioned, technologies standardized by OGC include CityGML, GML and KML. Formats from 3D computer graphics are standardized, for example, by ISO (International Organization for Standardization) or the Khronos Group. ISO standards are VRML and X3D. The Khronos group uses a standardized COLLADA format.

\subsection{Freeware and open source software for 3D modelling}

Software designed primarily for computer graphics, computer-aided drawing (CAD), photogrammetry, or GIS can be used when processing 3D geospatial data. Freely available 3D GIS software include the tools GRASS, LandSerf, 3DEM, and gvSIG with 3D extension. These software packages usually employ simple 3D visualization or 3D spatial analysis (in particular, GRASS). The 3D extension to gvSIG enables, for example, the extrusion of 2D geometry, the symbolisation of point layers, or the setting of stereo visualization. These tools also quite often allow the conversion of selected formats. Certain possibilities of 3D data processing are also provided through plug-ins (e.g. DEMto3D, Shp2D3, and Qgis2threejs) in the widespread open source software QGIS.

Trimble SketchUp, which is used regularly for the 3D modelling of buildings and other objects, is a CAD program working with 3D data. Regarding software for 3D 
computer graphics, commercial programs are often used. However, there are also the freeware applications MeshLab and View3DScene as well as the open source tools Blender and Wings 3D. The individual aforementioned applications are often combined in the process of creating 3D models. The key factor is then support for formats that are used to transfer data between applications. In these connections, it is appropriate to use standards (all formats specified in the previous section are standards). Price is also an important aspect when selecting 3D software, in addition to its functionality. In this study, we focus on non-commercially distributed applications (freeware and open source).

\subsection{D rendering in a web browser}

A broad spectrum of technologies is also available for rendering on the Web. In addition to thick clients, which are standalone applications such as Google Earth, there are a number of techniques for displaying 3D data using a simple web browser. Many of them use plug-ins. 3D models can be displayed in a web environment using Flash plug-in, version 11.0 or higher, or Microsoft Silverlight technology, version 3.0 or higher [4]. Plug-ins are also used for the implementation of virtual globes, for example NASA World Wind. Today, preference is given to technologies built on HTML5 and JavaScript library WebGL. These are, for example, SpiderGL, Three.js, XML3D and X3DOM. SpiderGL library is based on the COLLADA file structure [6]. Three.js was used for the implementation of 3D city model visualization by [38]. Practical aspects of the use of the X3DOM library for the 3D visualization of detailed models of cities are described, for example, by [8]. In addition to general 3D libraries, there are also a number of 3D virtual globes, e.g. OpenWebGlobe [20].

\section{Pilot study}

The data and technologies described in this paper were tested in the area around the Vltava River in Prague, the Czech Republic. The floods in 2002 were the most destructive floods in the history of Prague. The flow of the Vltava River culminated at $5300 \mathrm{~m}^{3} / \mathrm{s}$. About 40000 people were evacuated from immediate vicinity. The area around the Vltava was flooded again in 2013 (culmination at $3200 \mathrm{~m}^{3} / \mathrm{s}$ ).

\subsection{Open geospatial data in the Czech Republic}

The Registry of Territorial Identification, Addresses and Real Estate (RUIAN) in the Czech Republic became a freely available online resource for geospatial data in 2012. Among other data and attributes, this registry also contains information about number of floors per each building. On the basis of this information, 3D models can be created from building footprints. The dataset is downloadable and includes also address points, streets, parcels, administrative units, and electoral districts. [27]

There are also detail open data for city areas provided in the Czech Republic, e.g. Děčín, Plzeň and, above all, Prague. The Prague Institute of Planning and Develop- 
ment (IPR) manages and provides open data - specifically, open data for various purposes and analyses connected, for example, with power distribution, noise mapping, the climate, the environment, and flood protection. In addition to this kind of data, the datasets include 3D buildings, 3D towers, absolute and relative building heights, digital terrain models (DTM), or digital surface models (DSM). Similar data for 3D city models are also provided for cities around the world, e.g. Berlin, Hamburg, Montreal, Rotterdam and New York. [10, 22]

\subsection{Input data}

The following were used as input data for the creation of 3D models:

- The digital terrain model of the city Prague provided by IPR in TIFF format. This DTM was created from aerial photography in 2010 and designed for the level of detail commensurate with a map scale of 1:5000.

- Building footprints from RUIAN that are available on-line as a Web Feature Service or as off-the-shelf GML files (data are compressed by the GZIP algorithm).

- Flood areas for various water levels (for 5-, 20- and 100-year floods) provided by IPR as Shapefiles with Polygon geometry. Alternatively, Shapefiles for identical water levels from the DIBAVOD (Digital Base of Water Management Data) database can also be used, but these do not have a clearly defined license.

- Flood walls provided by IPR as Shapefiles with Polyline geometry.

- Orthophoto Prague 2015 with a pixel resolution of $50 \mathrm{~cm}$ and in true colors. Data acquisition took place in August 2015. Orthophoto is stored in TIFF format.

- POI (Points of Interest) from OSM downloaded from Geofabrik Tools. We used POI as a Shapefile with Point geometry.

\subsection{Processing of open data}

These input data were processed in QGIS software (version 2.12) with the same plugins which are intended for the processing and visualization of 3D data. The QGIS program enables the use of functions important for 3D data pre-processing (interpolation and other techniques of virtual surfaces creation). Available 3D plug-ins for QGIS are: Shp2D3, CZML Generator, and Qgis2threejs. Shp2D3 transforms 2D vector data to 3D by the sampling of an elevation raster map. It works actually only with polylines. CZML Generator serves to export to form ready for virtual globe (for Cesium library). Qgis2threejs exports terrain data, map canvas images, and vector data to a web browser which supports WebGL. This plug-in uses the Three.js library; thus, in this study, final visualization was implemented through this library.

In this pilot study (see Fig. 2), we used mainly Qgis2threejs for visualization in a web browser. All data are loaded into QGIS as GML, Shapefiles, and TIFF files. Additional layer settings (e. g. color scales for terrain) can be set through QGIS. Other parameters of final visualization, like template of final web page, controls, and other parameters of individual layers (e.g. exaggeration, display of labels, transparency, background color, resampling of raster) are defined in the scope of the Qgis2threejs plug-in. 


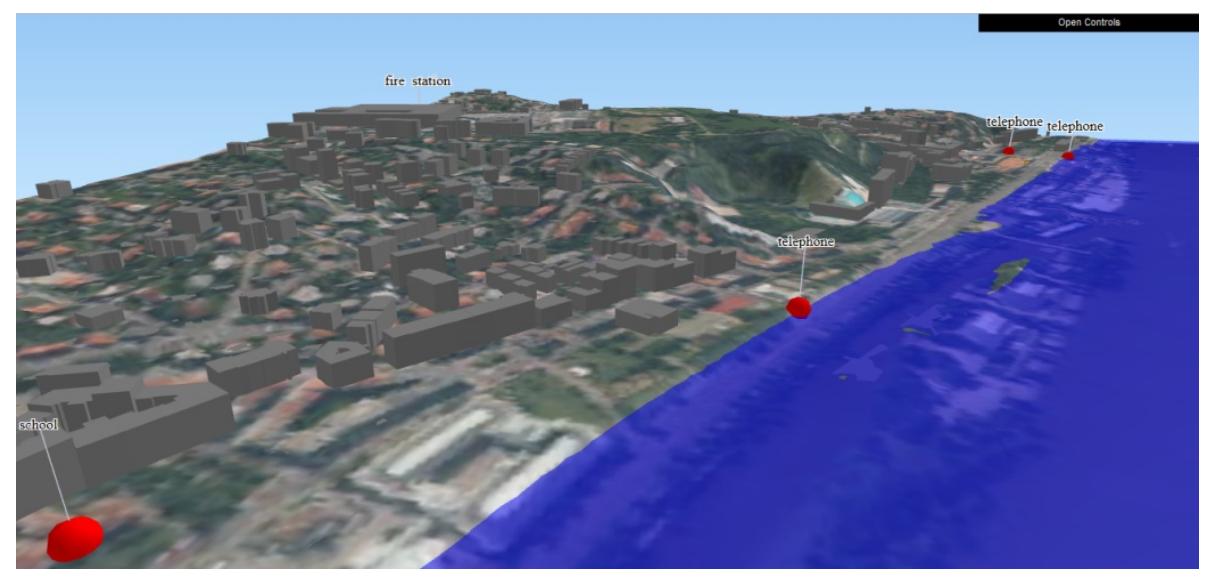

Fig. 2. Example of a web application for the 3D visualization of floods.

Three.js in final 3D visualization enables the basic functionality usually available in web map portals (see of Fig. 3 - left part). Users can switch between layers or set their transparency, because transparency avoids the occlusion of features or layers. One can create one's own "cut of plane" and simulate in this way the change of water level (shown in right part of Fig. 3).
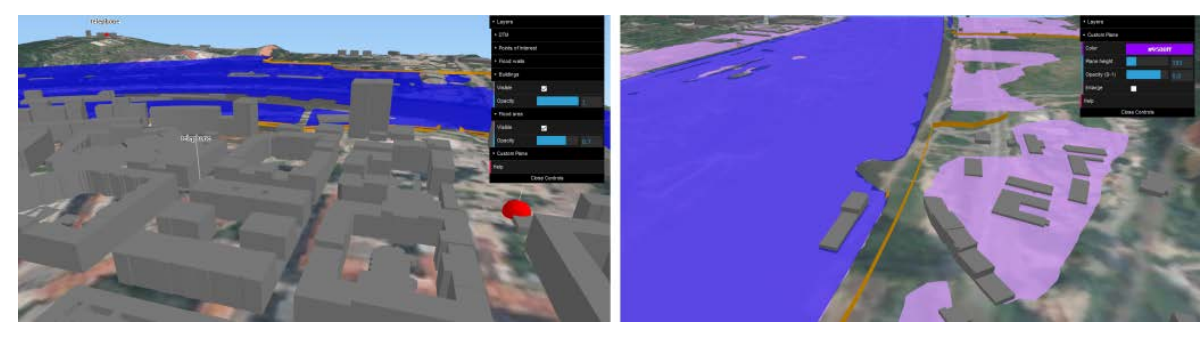

Fig. 3. Interactive functionality of developed application (left - setting parameters of layers, right - "cut of plane")

\section{Discussions}

$3 \mathrm{D}$ visualization in general has significant application potential, but it is affected by its properties, e.g. the UI (User Interface) or cartographic visualization methods. Regarding cartographic visualization, our approach is not directly dependent on the visualization(s) of underlying data. Cartographic visualization should be developed separately for each application and is not directly re-distributable since it is written directly in the Three.js code. We may define, for example, a standardized cartographic visualization for flood areas, flood walls, as well as POI using the developed software as shown in this paper. [15, 35] have focused on this issue.

The usability aspects of concrete UI are also important topics for future research. Some authors, e.g. [37], argue that 3D visualization is able to present geospatial data 
to wider audiences, including those with little or no cartographical or GIS experience. On the other hand, results of other previous studies [9, 12, 31] suggest that interactive $3 \mathrm{D}$ visualization will be more useful for users with previous experience with $3 \mathrm{D}$ visualization and for complex tasks in particular. It would be appropriate to validate created application through user testing.

When we focused on technological issues, we found that using Multipatch geometry for storing 3D open geodata limits the possibilities of 3D modeling in open source software which does not support this geometry (unlike Shapefiles with Point, Polyline or Polygon geometries). Multipatch geometry is supported only in commercial software (ESRI ArcGIS and FME), but not in QGIS or gvSIG. Buildings at the level of detail 1 (LoD 1) are modeled in the resulting application only. Web applications built with Three.js could be further tested in terms of capacity, availability and support in different Web browsers. Deployment in a form of daily service should be made after validations of above mentioned technological parameters.

\section{Conclusion}

The presented proof-of-concept application was established in order to demonstrate the possibility of open web-based 3D visualization. It should be emphasized that the openness relies on the data and software used, as well as on the final application. The developed proof-of -concept application is freely available to interested persons under a BSD license.

To sum up, the following major advantages of 3D visualization based on open data and Three.js library were identified:

- it represents (in this pilot study) an example of an open data application usable in flood impact analysis and crisis management;

- it enables user-friendly interactive 3D visualization, which is accessible to a broad spectrum of users (from the general public to experts);

- it does not require any new software or plug-ins to be installed on the client or server sides;

We also identified some limitations of available open source tools. The noncommercial software functionality needed for the creation of 3D visualizations is generally sufficient because, inter alia, programs primarily used in computer graphics can also be used for this purpose. Less commonly available is non-commercial software support for 3D analytical tools (3D equivalents of overlay algebra functions, calculations of surfaces or volumes of 3D elements).

We must also mention recommendations for the formats in which open ends are provided for 3D geospatial data. Multipatch geometry, which is used in the case of Prague open data for 3D models of buildings at the level of detail 2 (LoD 2), is not supported in open source tools such as QGIS. It is more suitable to transform these data into a standardized format like CityGML or into GML files formatted according to INSPIRE (INfrastructure for SPatial InfoRmation in Europe) data theme Buildings. 
Acknowledgements. This research was funded by Grant No. MUNI/A/1419/2016, "Integrated research on environmental changes in the landscape sphere of Earth II" and Grant No. MUNI/M/0846/2015, "Influence of cartographic visualization methods on the success of solving practical and educational spatial tasks”, both awarded by Masaryk University, Czech Republic.

\section{References}

1. 3D development. http://wiki.openstreetmap.org/wiki/3D_development

2. $5 \star$ Open Data. http://5stardata.info/en/

3. ASTER Global Digital Elevation Map Announcement. https://asterweb.jpl.nasa.gov/gdem.asp

4. Behr, J., Eschler, P., Jung, Y., Zöllner, M.: X3DOM - A DOM-based HTML5/ X3D Integration Model. In: Proceedings of Web3D 2009: The 14th International Conference on Web3D Technology, Web3D 2011, pp. 127-135 (2009)

5. Copernicus. http://www.copernicus.eu

6. Di Benedetto, M., Corsini, M., Scopigno, R.: SpiderGL: A Graphics Library for 3D Web Applications. International Archives of the Photogrammetry, Remote Sensing and Spatial Information Sciences, vol. XXXVIII-5/W16, pp. 467-474 (2011)

7. Goetz, M.: Towards generating highly detailed 3D CityGML models from OpenStreetMap. International Journal of Geographical Information Science 27(5), 845-865. (2013)

8. Herman, L. Reznik, T.: 3D Web Visualization of Environmental Information - Integration of Heterogeneous Data Sources when Providing Navigation and Interaction. In: ISPRS Archives of the Photogrammetry, Remote Sensing and Spatial Information Sciences, vol. XL3/W3, pp. 479-485 (2015)

9. Herman, L., Stachon, Z.: Comparison of User Performance with Interactive and Static 3D Visualization - Pilot Study. In: ISPRS Archives of the Photogrammetry, Remote Sensing and Spatial Information Sciences, vol. XLI-B2, pp. 655-661 (2016)

10. IPR Praha - Institut plánování a rozvoje hlavního města Prahy [IPR Praha - Prague Institute of Planning and Development]. http://www.iprpraha.cz/

11. Keler, A., Mazimpaka, J. D.: Safety-aware routing for motorised tourists based on open data and VGI. Journal of Location Based Services 10(1), 64-77 (2016)

12. Jurik, V., Herman, L., Sasinka, C., Stachon, Z., Chmelik, J.: When the display matters: A multifaceted perspective on 3D geovisualizations. Open Geosciences 9(1) [in print] (2017)

13. Kolbe, T. H.: Representing and exchanging 3D city models with CityGML. In: Lee, J., Zlatanova, S. (eds.) 3D Geo-information Sciences, pp. 15-31. Springer, Heidelberg (2009)

14. Konecny, M.: Cartography: Challenges and Potentials in Virtual Geographic Environments Era. Annals of GIS 17(3), 135-146 (2011)

15. Konecny, M., Kubicek, P., Stachon, Z. Sasinka, C.: The usability of selected base maps for crises management - Users' perspectives. Applied Geomatics 3(4), 189-198 (2011)

16. Kubasek, M.: Mapping of Illegal Dumps in the Czech Republic - Using a Crowd-Sourcing Approach. In: Environmental Software Systems. Fostering Information Sharing, IFIP Advances in Information and Communication Technology, vol. 413. pp. 177-187 (2013)

17. Kubicek, P., Mulickova, E., Konecny, M., Kucerova, J.: Flood Management and Geoinformation Support within the Emergency Cycle (EU Example). In: Environmental Software Systems. Frameworks of eEnvironment, IFIP Advances in Information and Communication Technology, vol. 359. pp. 77-86 (2011) 
18. Long, Y., Liu, L.: Transformations of urban studies and planning in the big/open data era: a review. International Journal of Image and Data Fusion 7(4), 295-308 (2016)

19. Mooney, P., Corcoran, P.: Has OpenStreetMap a Role in Digital Earth Applications? International Journal of Digital Earth 7 (7), 534-53 (2014)

20. Netek, R., Loesch, B., Christen, M.: OpenWebGlobe - Virtual Globe in Web Browser. SGEM - Geoconference on Informatics, Geoinformatics and Remote Sensing - Conference Proceedings, vol. 1. pp. 497-503 (2013)

21. O’Brien, O., Cheshire, J.: Interactive mapping for large, open demographic data sets using familiar geographical features. Journal of Maps 12 (4), 676-683 (2016)

22. Open Data Initiatives. http://www.citygmlwiki.org/index.php/Open_Data_Initiatives

23. OpenStreetMap. https://www.openstreetmap.org

24. Palma, R., Reznik, T., Esbri, M., Charvat, K., Mazurek, C.: An INSPIRE-Based Vocabulary for the Publication of Agricultural Linked Data. In 12th International Experiences and Directions Workshop on OWL, pp. 124-133 (2016)

25. Reznik, T., Lukas, V., Charvat, K., Charvat, K. jr, Horakova, S, Krivanek, Z., Herman, L.: Monitoring of In-Field Variability for Site Specific Crop Management Through Open Geospatial Information. In ISPRS Archives of the Photogrammetry, Remote Sensing and Spatial Information Sciences, vol. XLI-B8, pp. 1023-1028 (2016)

26. Roy, D. C., Coors, V.: 3D web-based GIS for flood visualization and emergency response. In: 73rd European Association of Geoscientists and Engineers Conference and Exhibition 2011: Unconventional Resources and the Role of Technology, vol. 2, pp. 1001-1005 (2011)

27. RÚIAN [RUIAN]. http://www.cuzk.cz/ruian/RUIAN.aspx

28. Russnak, J., Ondrejka, P., Herman, L., Kubicek, P., Mertel, A.: Visualization and Spatial Analysis of Police Open Data as a Part of Community Policing in the City of Pardubice (Czech Republic). Annals of GIS 22 (3), 187-201 (2016)

29. Shuttle Radar Topography Mission. http://www2.jpl.nasa.gov/srtm/dataprod.htm

30. Simple 3D buildings. http://wiki.openstreetmap.org/wiki/Simple_3D_buildings

31. Sprinarova, K., Jurik, V., Sasinka, C., Herman, L., Sterba, Z., Stachon, Z., Chmelik, J., Kozlikova, B.: Human-computer Interaction in Real 3D and Pseudo-3D Cartographic Visualization: A Comparative Study. In: Cartography - Maps Connecting the World: 27th International Cartographic Conference 2015 - ICC2015, pp. 59-73 (2015)

32. SRTM DEM. http://www.gisat.cz/content/cz/produkty/digitalni-model-terenu/srtm-dem

33. Stachon, Z., Kubicek, P., Stampach, R., Herman, L., Russnak, J., Konecny, M.: Cartographic Principles for Standardized Cartographic Visualization for Crisis Management Community. In: Proceedings, 6th International Conference on Cartography and GIS, vol. 1 and vol. 2, pp. 781-788 (2016)

34. The Open Definition. http://opendefinition.org

35. Van Ackere, S., Glas, H., Beullens, J., Deruyter, G., De Wulf, A., De Maeyer, P. (2016) Development of a 3D dynamic flood WEB GIS visualisation tool. International Journal of Safety and Security Engineering 6 (3), 560-569 (2016)

36. Vijith, H., Seling, L. W., Dodge-Wan, D.: Comparison and Suitability of SRTM and ASTER Digital Elevation Data for Terrain Analysis and Geomorphometric Parameters: Case Study of Sungai Patah Subwatershed (Baram River, Sarawak, Malaysia). Environmental Research, Engineering and Management 71 (3), 23-35 (2015)

37. Vozenilek, V.: Cartography for GIS: Geovisualization and Map Communication. Univerzita Palackého, Olomouc (2005)

38. Wendel, J. Murshed, S. M., Sriramulu, A., Nichersu, A.: Development of a Web-Browser Based Interface for 3D Data - A Case Study of a Plug-in Free Approach for Visualizing Energy Modelling Results. In: Progress in Cartography. pp 185-205 (2016) 